\title{
RETRACTED ARTICLE: Laboratory Study of Three- Dimensional Crack Propagation in Rock-Like Material Under Uniaxial Compression
}

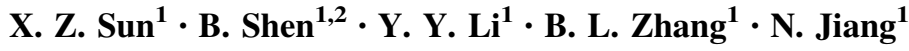

Received: 19 November 2015/ Accepted: 16 June 2016/Published online: 8 July 2016

(C) Springer-Verlag Wien 2016

This paper has been retracted by decision of the Editor in Chief, given that the same paper has been previously published in the Chinese Journal "Rock and Soil Mechanics". The Authors did not make this clear to the journals involved and did not reference the first publication. The online version of this article contains the full text of the retracted article as electronic supplementary material.

Electronic supplementary material The online version of this article (doi:10.1007/s00603-016-1033-x) contains supplementary material, which is available to authorized users.

Y. Y. Li

sunxizhen2008@126.com

1 State Key Laboratory of Mining Disaster Prevention and Control Co-founded by Shandong Province and the Ministry of Science and Technology, Shandong University of Science and Technology, 579 Qianwangang Road Economic and Technical Development Zone, Qingdao 266590, Shandong Province, People's Republic of China

2 Commonwealth Scientific and Industrial Research Organisation (CSIRO) Energy, P.O. Box 883, Kenmore, Brisbane, QLD 4069, Australia 